\title{
DESENVOLVIMENTO AGROECONÔMICO DO CONSÓRCIO NABO COM CEBOLINHA EM SISTEMA ORGÂNICO DE PRODUÇÃO
}

\author{
Sandy Queiroz Espinoso' \\ Matheus Wandermurem da Silva ${ }^{2}$ \\ Diego Souza Tosta ${ }^{3}$ \\ Samayana Inacio Delprete ${ }^{4}$ \\ Wallace Luiz Lima $^{5}$ \\ Arnaldo Henrique de Oliveira Carvalho ${ }^{6}$
}

Resumo: O experimento foi realizado no Setor de Agroecologia do Ifes Campus de Alegre, o arranjo experimental foi delineamento de blocos casualizados, com quatro repetições, os tratamentos constituíram por monocultivo de nabo, monocultivo de cebolinha e três diferentes combinações de populações de plantas, para cada uma das duas culturas. O objetivo do trabalho foi avaliar a produtividade e a renda bruta do nabo e a cebolinha, obtidas com o cultivo solteiro e consorciado, características agronômicas, aproveitamento da área de cultivo consorciado através do uso eficiente da terra em relação ao monocultivo, visando oferecer aos produtores uma alternativa de manejo mais eficaz para essas duas culturas, que seja mais sustentável e mais rentável. Foram avaliados para cebolinha o número de perfilho, número de folha, comprimento da maior folha $(\mathrm{cm})$, massa fresca $(\mathrm{kg})$ e número de molhos, determinando 50 folhas para cada molho, para padronizar a produtividade. Para o nabo foram avaliados o diâmetro do tubérculo, comprimento do tubérculo $(\mathrm{cm})$, comprimento parte aérea $(\mathrm{cm})$, massa fresca do tubérculo $(\mathrm{kg})$ e número de folhas.

Palavras-chave: Consórcio; Agricultura orgânica; Hortaliças; Olericultura.

\footnotetext{
1 Tecnologia em Cafeicultura/Instituto Federal do Espírito Santo - Campus de Alegre, Brasil. E-mail: sandyespinoso@gmail.com.

2 Instituto Federal do Espírito Santo Campus de Alegre, Brasil. E-mail: matheus_wandermurem@hotmail.com.

${ }^{3}$ Instituto Federal do Espírito Santo Campus de Alegre, Brasil. E-mail: diego.s.tosta@gmail.com.

4 Ciências Biológicas/Instituto Federal do Espirito Santo - Campus Alegre, Brasil. E-mail: samayana97@gmail.com.

${ }^{5}$ Instituto Federal do Espírito Santo Campus de Alegre, Brasil. E-mail: limawl@yahoo.com.br.

6 Orientador/Instituto Federal do Espírito Santo - Campus de Ibatiba, Brasil. E-mail: arnaldohenrique.carvalho@gmail.com.
} 